Original article

\title{
Uncontrolled asthma determinants in overweight and obese adults
}

\author{
Vitaly I. Kupaev, Olga V. Sazonova, Maria S. Nurdina, Lyubov M. Borodina, Mikhail Yu. Gavryushin, \\ Dmitry O. Gorbachev
}

Samara State Medical University, Samara, Russia

Received 18 November 2020, Revised 6 May 2021, Accepted 22 September 2021

CC 2020, Russian Open Medical Journal

Abstract: Relevance of the research - epidemiological and clinical studies in recent years confirmed the existence of a bronchial asthma (BA) phenotype associated with obesity. In the current literature, obesity is considered a possible risk factor for the development of BA. Nonetheless, the factors contributing to the uncontrolled course of BA among overweight patients need to be elucidated. The need for a personalized approach to patient management is reflected in the latest edition of the international consensus document on the asthma treatment - GINA (Global Initiative for Asthma: Global Strategy for Asthma Management and Prevention). Despite substantial number of epidemiological studies on the prevalence of BA in obese patients, the threshold values of major risk factors for the development of uncontrolled BA (vitamin D, IL-17, IL-10, BMI; intake of total fat, carbohydrates and cholesterol) remain unclear. Objective: to identify the risk of developing an uncontrolled course of BA depending on the levels of IL-17, IL-10 and vitamin D; dietary characteristics (intake of total fat, cholesterol and carbohydrates); and body mass index (BMI).

Material and methods - The study involved 79 patients with an established diagnosis of BA, 18-69 years old. Patients were split among three groups according to their BMI values. Group I included 27 patients with normal body weight (BMI: $\left.18.5-24.9 \mathrm{~kg} / \mathrm{m}^{2}\right), 56(42-61)$ years of age. Group II comprised 28 overweight patients (BMI: $\left.25-30 \mathrm{~kg} / \mathrm{m}^{2}\right), 57$ (50.5-63.5) years of age; Group III encompassed 24 obese patients (BMI $\left.\geq 30 \mathrm{~kg} / \mathrm{m}^{2}\right), 58(54-65)$ years of age.

Results - the risk of developing uncontrolled BA increased by 1.8 times with increase of a total fat intake $(95 \% \mathrm{Cl}: 1.28-2.72 ; \mathrm{p}=0.001) ;$ by 5.7 times with $\mathrm{BMI}>26.7 \mathrm{~kg} / \mathrm{m}^{2}$ (95\% Cl:2.05-15.92; $\left.\mathrm{p}<0.001\right)$; by 5.2 times with IL-17 level >83.5 pg/mL (95\% Cl:1.71-15.8; $\left.\mathrm{p}=0.003\right) ;$ by 8.32 times with vitamin $\mathrm{D}$ content $<24.5 \mathrm{ng} / \mathrm{mL}(95 \% \mathrm{Cl}: 2.9-23.72 ; \mathrm{p}<0.001)$.

Conclusion - patients with BMl $>26.7 \mathrm{~kg} / \mathrm{m}^{2}$, vitamin D deficiency (i.e., vitamin D content $<24.5 \mathrm{ng} / \mathrm{mL}$ ), IL- $17 \mathrm{content}>83.5 \mathrm{pg} / \mathrm{mL}$, as well as excessive consumption of total fat, carbohydrates and cholesterol, could be attributed to the risk group for developing an uncontrolled BA.

Keywords: bronchial asthma, body mass index, BMI, vitamin D, obesity, actual nutrient intake.

Cite as Kupaev VI, Sazonova OV, Nurdina NS, Borodina LM, Gavryushin MYu, Gorbachev DO. Uncontrolled asthma determinants in overweight and obese adults. Russian Open Medical Journal 2021; 10: e0407.

Correspondence to Olga V. Sazonova. Address: Institute of Preventive Medicine, 89 Chapaevskaya St., Samara 443099, Russia. Phone: +7 (846) 374 1004 / 4711. E-mail: ov_2004@mail.ru.

\section{Introduction}

Currently, achieving a controlled course of bronchial asthma (BA) is the main goal of therapeutic treatment [1]. Despite all achievements of contemporary pharmacotherapy and introduction of novel genetically engineered medications, there is still a substantial number of patients with uncontrolled BA [2]. As a result, patients in this group have a high risk of exacerbations, hospitalizations, and a low level of their quality of life [3]. We should also point out the high cost of medical treatment of patients with uncontrolled BA. According to the State Register of Marginal Selling Prices (SRMSP) as of 06 April, 2019, the cost of treatment with the genetically engineered drug omalizumab exceeds 1 million rubles per patient per year (calculated for a course of 26 injections) [4, 5]. In European countries, the economic burden of BA has been significantly reduced through the introduction of easy-to-use disease control tools [6]. Furthermore, non-pharmacological correction of the BA course is a promising vector of development. The introduction of a personalized approach to the treatment of BA into actual clinical practice, taking into account the predicted risks of developing an uncontrolled course of the disease, could significantly increase the level of control over BA and stimulate patients' adherence to treatment [7-9].

Epidemiological data indicate the prevalence of BA among obese patients [10]. A number of studies demonstrated that obesity aggravated airway inflammation and the severity stages of BA. However, the pathogenetic mechanisms underlying this relationship are not sufficiently clear [11]. The immunological theory of the uncontrolled BA development is widely discussed in current publications. The key role is assigned to proinflammatory (IL-17) and anti-inflammatory (IL-10) cytokines [12]. Nevertheless, their role in BA against the background of obesity is ambiguous and requires further investigation. 
A number of authors confirmed the effect of vitamin $D$ on humoral and cellular immunity in in vitro experiments [13]. However, none of the studies has conducted a comprehensive assessment of the individual actual nutrient intake in BA patients, in conjunction with a biochemical study of the levels of vitamin $D$, IL-10, and IL-17 in the blood serum.

A large number of BA patients have a stereotypical idea of the need to follow a hypoallergenic diet, consequently restraining from the intake of a number of products. Fruits and vegetables are often excluded, which can lead to a higher intake of simple carbohydrates and fats in the diet [14].

Research objective: to determine the risk of developing uncontrolled BA, depending on the levels of IL-17, IL-10, vitamin D, dietary characteristics (total fat, carbohydrates, cholesterol), and body mass index (BMI).

\section{Material and Methods}

\section{Research design}

The study involved 79 patients with an established diagnosis of BA. Their median age was 57 (50-63) years. Of these, $22(27.8 \%)$ were men and $57(72.2 \%)$ were women. The study groups were dominated by patients with BA phenotype $\left(\chi^{2}=10.97, p=0.005\right)$. We compared the BA severity stages (mild, moderate, or severe), the level of BA control, the content of proinflammatory cytokine IL-17 and anti-inflammatory cytokine $\mathrm{IL}-10$, as well as the level of vitamin $\mathrm{D}$ among overweight and obese patients, compared with the patients with a normal body weight. Based on the obtained data, the risks of developing an uncontrolled course of $A D$ were calculated. The structure of the surveyed patient sample is presented in Table 1.

As can be seen from Table 1, the patients were divided into three groups: patients with normal BMI (Group I), overweight patients (Group II), and obese subjects (Group III). The body mass index was assessed sensu WHO classification: normal body weight corresponded to BMI values of $18.5-24.9 \mathrm{~kg} / \mathrm{m}^{2}$; overweight status was defined by the BMI of $25-29.9 \mathrm{~kg} / \mathrm{m}^{2}$; obese subjects had BMI of $>30 \mathrm{~kg} / \mathrm{m}^{2}$.

The groups were comparable in terms of gender $(\chi 2=-0.887$, $p=0.62)$ and age $(p>0.05)$ compositions. Patients were statistically significantly different in terms of the values yielded by the asthma control test (ACT) and FEV1 (forced expiratory volume in the first second).

\section{Description of medical intervention}

The medical examination included a physical examination of patients (collection of their complaints, preparation of their anamneses), anthropometric measurements, spirometry with an assessment of the forced expiratory volume in the first second (FEV1) before and after the test with a bronchodilator. The severity stages of BA (mild, moderate, or severe), the phenotype, and the degree of control were evaluated, based on the criteria of the Global Asthma Initiative 2019 (GINA).

All patients underwent the ACT. The sum of points on the questionnaire fewer than 20 was considered an uncontrolled course of BA, whereas more than 20 was interpreted as the controlled BA course.

To evaluate the structure of patients' nutrition, a surveyweight method was used. All participants kept food diaries for 21 days in a row, on the basis of which, the daily diet was subsequently analyzed. Prior to the study, all respondents received a standardized form to fill out, and were given detailed instructions on keeping their food diary, as well as on weighing foods and dishes. The diary provided detailed information on all daily meals and snacks, and reflected the following indicators: the time of the meal, the name of the dish or food item, the weight of the serving, the composition of the dish, the weight of the dish components. Additional notes indicated the macronutrient composition and caloric value of the consumed foods.

The caloric values and chemical composition of the food products were calculated on the basis of the data provided by VA Tutelyan in his Handbook of Dietetics (2002) [15]. The evaluation of the obtained results was carried out in accordance with the requirements of the Guidelines 2.3.1.2432-08 'Norms of Physiological Needs in Energy and Nutrients for Various Groups of the Russian Federation Population'.

The ELISA technique was used to study the content of IL-17, IL10 , and the level of vitamin $D$ in the blood serum. The determination of the serum IL-10 and IL-17 content was carried out using commercial kits for conducting solid-phase enzyme immunoassay (TIFA) of the Cytokine company (Russia), in accordance with the manufacturer's instructions. The study was carried out on the automatic analyzer, Multiskan ${ }^{\text {TM }}$, Thermo Fisher Scientific (USA). Identification of vitamin 25(OH)D (25hydroxycholecalciferol) content in the blood serum was performed using commercial ELISA kits from BioChemMak, JSC (Russia), manufactured by DIAsource ImmunoAssays (Belgium). In vitamin 25(OH)D ELISA kits, a sandwich version of TIFA was used.

Table 1. Characteristics of the examined patient groups

\begin{tabular}{|c|c|c|c|c|}
\hline Parameters & $\begin{array}{c}\text { Normal BMI } \\
\text { (Group I) } n=27\end{array}$ & $\begin{array}{l}\text { Overweight adults } \\
\text { (Group II) } n=28\end{array}$ & $\begin{array}{c}\text { Obese adults } \\
\text { (Group III) } n=24\end{array}$ & $\begin{array}{c}\text { Statistical } \\
\text { significance }\end{array}$ \\
\hline Age, years & $56(42-61)$ & $57(50.5-63.5)$ & $58(54-65)$ & $p>0.05$ \\
\hline Men, number (\%) & $8(29.6 \%)$ & $9(32.1 \%)$ & $5(20.8 \%)$ & \multirow{2}{*}{$\chi^{2}=-0.887 p=0.62$} \\
\hline Women, number (\%) & $19(70.4 \%)$ & $19(67.9 \%)$ & $19(79.2 \%)$ & \\
\hline$A C T$, points & $25(23-25)^{*}$ & $23(17-25)$ & $15(10-23)$ & $p<0.05$ \\
\hline FEV1 (L) & $2.32(1.91-2.68)^{*}$ & $2.09(1.88-2.67)$ & $1.81(1.39-2.31)$ & $p<0.05$ \\
\hline FEV1 (\%) & $99(87-108)^{*}$ & $94(84.5-102.5)$ & $80.5(62-94.5)$ & $p<0.05$ \\
\hline Allergic asthma phenotype, number (\%) & $22(81.5 \%)$ & $19(67.9 \%)$ & $9(37.5 \%)$ & \multirow{2}{*}{$\chi^{2}=10.9 p<0.05$} \\
\hline BA with the late onset, number (\%) & $5(18.5 \%)$ & $9(32.1 \%)$ & $15(62.5 \%)$ & \\
\hline
\end{tabular}

* Comparative analysis of the values (Group I vs. Group III). BMI, body mass index; ACT, asthma control test; FEV1, the forced expiratory volume in the first second; BA, bronchial asthma. 
Before the study, all participants signed a written consent to participate. Depending on how well the data matched normal distribution, the following calculated indicators were used to describe the quantitative data: Me (IQR), where Me is the median, and IQR is an interquartile range between the values of $25^{\text {th }}$ and $75^{\text {th }}$ percentiles. As for statistical analysis, the methods of descriptive statistics and the method of identifying the statistical significance of differences (the Mann-Whitney $U$ test) were employed. The comparison quantitative among three independent groups with distributions different from the normal distribution was performed using the Kruskal-Wallis test. The comparisons of discrete variables among different groups was carried out using the standard method of analyzing the contingency tables $\left(\chi^{2}\right.$ sensu Pearson).

Logistic regression was used to determine the nonlinear relationships of binary variables with qualitative and/or quantitative parameters. The odds ratio (OR), i.e., an occurrence of an adverse event, and the $95 \%$ confidence interval $(\mathrm{Cl})$ were calculated.

To assess the effects of body weight and vitamin $D$ on the course of BA, the ROC curve analysis (Receiver Operating Characteristic) was used. To obtain a numerical value of the effect of obesity on the course of BA, we estimated the Area Under the Curve (AUC).

The obtained results were processed using the Statistica v.10 program, and the differences were considered statistically significant at $p<0.05$.

\section{Results}

Physical and instrumental examination of patients with a normal body weight revealed statistically significantly lighter course of BA, compared with overweight and obese patients $\left(\chi^{2}=10.9, p<0.05\right)$ (Table 2).

Table 2. Stages of bronchial asthma severity versus BMI

\begin{tabular}{lccc}
\hline BA severity stages & \multicolumn{3}{c}{ Groups } \\
\hline Mild BA & I $\mathrm{n}=27$ & $\mathrm{II} \mathrm{n}=28$ & $\mathrm{III} \mathrm{n}=24$ \\
Moderate BA & $13(48.2 \%)$ & $7(25 \%)$ & $2(8.3 \%)$ \\
Severe BA & $12(44.4 \%)$ & $18(64.2 \%)$ & $17(70.8 \%)$ \\
\hline
\end{tabular}

$\chi^{2}=10.9 ; p<0.05$. BA, bronchial asthma; $B M I$, body mass index.

Table 3. Asthma control versus BMI

\begin{tabular}{lcc}
\hline BMI-based groups & Controlled BA (100\%) & Uncontrolled BA (100\%) \\
\hline Group I $\mathrm{n}=27$ & $22(45.8 \%)$ & $5(16.1 \%)$ \\
Group II $\mathrm{n}=28$ & $17(35.4 \%)$ & $11(35.5 \%)$ \\
Group III $\mathrm{n}=24$ & $9(18.8 \%)$ & $15(48.4 \%)$ \\
\hline
\end{tabular}

$\chi^{2}=10.31 ; p<0.05$. BMI, body mass index.
All patients received basic anti-inflammatory therapy with inhaled glucocorticosteroids (IGCS), depending on the BA stage. Baseline therapy was evaluated in accordance with low, medium and high doses of IGCS according to the International Consensus. The majority of patients received IGCS in medium doses [43 (54.4\%) patients]; high doses were used by 11 (13.9\%) and low doses were used by 25 (31.7\%) patients.

Based on anamnesis and ACT data, controlled BA was established in 22 (45.8\%) patients with normal BMI, 17 (35.1\%) overweight patients, and 9 (18.75\%) obese subjects. Uncontrolled BA was detected in $5(16.1 \%)$ patients with normal BMI, $11(35.5$ $\%$ ) overweight patients, and 15 (48.8\%) obese participants (Table 3).

According to the study, the energy value of the daily diet exceeded the upper limit of the energy requirement for obese and overweight patients. E.g., in Group II, the daily energy consumption was 2520.9 (2250.8-2765.8) Kcal/day, whereas the upper limit of energy demand was just 2096.5 (1845.5-2322) $\mathrm{Kcal} /$ day $(\mathrm{U}=169, \mathrm{Z}=3.65, \mathrm{p}<0.001)$. In Group III, these numbers were 3522.7 (2970-4398) Kcal and 2290 (2168-2500) Kcal, respectively $(U=24, Z=5.43, p<0.001)$

The analysis of the actual nutrient intake showed an unbalanced diet in all studied groups of patients. Accordingly, in Groups I and II, an excess of carbohydrates' intake was detected (79\% and $80.7 \%$, respectively, of the total caloric content of consumed food). In Group III, there was an increase in the intake of total fat from food, including at the expense of saturated fatty acids (SFA) (41.4\%)

The diet of patients with uncontrolled BA was characterized by a higher intake of total fat, SFA, cholesterol, and carbohydrates, compared with the diet in subjects with controlled BA. Hence, the total fat consumption among these patients was 161.0 (101.3218.9) g/day, protein intake was 96.0 (79.3-117.7) g/day; SFA were consumed in the amount of $45.6(31.2-69.6) \mathrm{g} /$ day and total carbohydrates' intake was 439.9 (326.9-570.1) g/day (Table 4).

In a one-dimensional logistic model of the BA course, the predictors for the development of an uncontrolled BA course included an increase in the consumption of total fat (including SFA), cholesterol, and total carbohydrates; along with an increase in the caloric value of consumed food (Table 5).

In the multivariate logistic model of BA, the only predictor of uncontrolled BA development was associated with the level of total fat consumption.

Table 4. Consumption of essential nutrients by patients with asthma

\begin{tabular}{|c|c|c|c|c|}
\hline \multirow{2}{*}{ Parameters } & Controlled BA & Uncontrolled BA & \multirow{2}{*}{$U$} & \multirow{2}{*}{$\mathrm{p}$} \\
\hline & $\mathrm{Me}(\mathrm{IQR})$ & Me (IQR) & & \\
\hline Total fat, g/d & $89.1(61.7-130.3)$ & $161.0(101.3-218.9)$ & 399.0 & 0.001 \\
\hline SFA, mg/d & $35.9(25.6-45.6)$ & $45.6(31.2-69.6)$ & 450 & 0.003 \\
\hline Proteins, g/d & $67.5(56.6-88.0)$ & $96.0(79.3-117.7)$ & 376.0 & $<0.001$ \\
\hline Common carbohydrates, g/d & $300.5(223.6-408.4)$ & $439.9(326.9-570.1)$ & 413.0 & 0.001 \\
\hline
\end{tabular}

SFA, saturated fatty acids; Me, median; IQR, interquartile range. 
In order to determine the probability of developing an uncontrolled course of BA against the background of excess body weight, we conducted the ROC analysis. The AUC for BMI was 0.26 (95\% Cl: 0.15-0.377; $\mathrm{p}<0.001)$. The threshold value for $\mathrm{BMI}$ was $26.7 \mathrm{~kg} / \mathrm{m}^{2}$ (sensitivity: $64 \%$; specificity: $77 \%$ ). The odds ratio of developing uncontrolled $\mathrm{BA}$ at $\mathrm{BMI}>26.7 \mathrm{~kg} / \mathrm{m}^{2}$ was $5.7(95 \% \mathrm{Cl}$ : 2.05-15.92; $\mathrm{p}<0.001$ ) (Table 6). According to our results, it is arguable that the risk of developing uncontrolled BA is higher among overweight patients.

In order to determine the probability of developing an uncontrolled course of BA against the background of excess body weight, we conducted the ROC analysis. The AUC for BMI was 0.26 (95\% Cl: 0.15-0.377; $\mathrm{p}<0.001$ ). The threshold value for BMI was $26.7 \mathrm{~kg} / \mathrm{m}^{2}$ (sensitivity: $64 \%$; specificity: $77 \%$ ). The odds ratio of developing uncontrolled $\mathrm{BA}$ at $\mathrm{BMI}>26.7 \mathrm{~kg} / \mathrm{m}^{2}$ was $5.7(95 \% \mathrm{Cl}$ : 2.05-15.92; $\mathrm{p}<0.001$ ) (Table 6). According to our results, it is arguable that the risk of developing uncontrolled $B A$ is higher among overweight patients.

Evaluation of IL-17 levels in patients with BA revealed statistically significant differences between Group I and Group III. When comparing Groups I and II, no statistically significant differences in the levels of IL-17 were detected $(U=277, Z=-1.18$, $\mathrm{p}=0.09$ ) (Table 7).

IL-17 content increased with an increase in BMI in the group with controlled BA $(r=0.29, p<0.05)$. There was no statistically significant association between IL-10 and BMI.

In order to determine the probability of developing an uncontrolled course of BA with increase in IL-17 content, we performed the ROC analysis. The AUC for IL-17 was $0.29(95 \% \mathrm{Cl}$ : 0.19-0.43; $\mathrm{p}=0.003$ ). The threshold value for IL-17 was $83.5 \mathrm{pg} / \mathrm{mL}$ (sensitivity: $50 \%$; specificity: $80 \%$ ). The odds ratio for developing uncontrolled BA at IL-17 >83.5 pg/mL was 5.2 (95\% Cl: 1.71-15.8; $\mathrm{p}=0.003$ ) (Table 6).

Vitamin D levels were significantly dependent on BMI. The median vitamin D level was 31 (25.2-34.5) $\mathrm{ng} / \mathrm{mL}$ for patients with normal BMI, 25.5 (18.2-28.9) $\mathrm{ng} / \mathrm{mL}$ for overweight patients, and $18(15.5-23.6) \mathrm{ng} / \mathrm{mL}$ for obese patients (Table 8).

Table 5. The effect of actual nutrient intake on the risk of uncontrolled bronchial asthma

\begin{tabular}{lcc}
\hline Parameters & OR $(95 \% \mathrm{Cl})$ & $p$ \\
\hline Energy value & $1.04(1.02-1.07)$ & 0.002 \\
Common fat & $1.87(1.28-2.72)$ & 0.001 \\
SFA & $5.68(1.68-19.24)$ & 0.005 \\
Common carbohydrates & $1.25(1.08-1.44)$ & 0.003 \\
\hline
\end{tabular}

SFA, saturated fatty acids; $\mathrm{OR}$, odds ratio; $\mathrm{Cl}$, confidence interval.

Table 6. The effect of BMI, IL-17 and vitamin D levels on the risk of uncontrolled bronchial asthma

\begin{tabular}{lcc}
\hline Parameters & OR $(95 \% \mathrm{Cl})$ & $\mathrm{p}$ \\
\hline $\mathrm{BMI}>26.7 \mathrm{~kg} / \mathrm{m}^{2}$ & $5.7(2.05-15.92)$ & $\mathrm{p}<0.001$ \\
$\mathrm{IL}-17>83.5 \mathrm{pg} / \mathrm{mL}$ & $5.2(1.71-15.8)$ & $\mathrm{p}=0.003$ \\
Vitamin $\mathrm{D} \leq 24.5 \mathrm{ng} / \mathrm{mL}$ & $8.32(2.9-23.72)$ & $\mathrm{p}<0.001$ \\
\hline
\end{tabular}

$\mathrm{OR}$, odds ratio; $\mathrm{Cl}$, confidence interval; $\mathrm{BMI}$, body mass index.
The AUC for vitamin D was $0.844(95 \% \mathrm{Cl}: 0.760-0.928$; p<0.001). Threshold value: $24.5 \mathrm{ng} / \mathrm{mL}$ (sensitivity: 77\%; specificity: $70 \%$ ). The ratio of the chances to develop an uncontrolled course of BA at the level of vitamin D $<24.5 \mathrm{ng} / \mathrm{mL}$ was 8.32 (95\% Cl: 2.9-23.72, p<0.001) (Table 6).

Hence, overweight patients with vitamin $D$ deficiency (vitamin D level $<24.5 \mathrm{ng} / \mathrm{mL}$ ) and $\mathrm{IL}-17$ level $>83.5 \mathrm{pg} / \mathrm{mL}$ could be attributed to the risk group for developing the uncontrolled BA.

Hence, overweight patients with vitamin D deficiency (vitamin D level $<24.5 \mathrm{ng} / \mathrm{mL}$ ) and $\mathrm{IL}-17$ level $>83.5 \mathrm{pg} / \mathrm{mL}$ could be attributed to the risk group for developing the uncontrolled BA.

\section{Discussion}

The cause of the imbalance between the immunoregulatory subpopulations of T-lymphocytes, leading to the development of severe uncontrolled BA, remains debatable [16]. Currently, exogenous factors affecting the immune response formation began attracting greater attention. Among important risk factors for the development of uncontrolled BA, we should mention overweight status and obesity. A number of studies demonstrated that patients with BA against the background of obesity have a more severe course of the disease [17]. A progressive increase in BMI can lead to the formation of a specific BA phenotype. BA against the background of obesity is characterized mainly by neutrophilic inflammation in the respiratory tract and an increase in IL-17 production $[18,19]$.

Our study showed a significant increase in the level of proinflammatory cytokine IL-17 in the group of patients with uncontrolled BA and overweight status, which could explain the more severe course of BA among obese patients. There were no statistically significant differences between the IL-10 level and $\mathrm{BMI}$. The prospects for personalized therapy of BA are associated with identification of biomarkers, determining the uncontrolled $B A$ course, in particular, with the level of IL-17.

In the course of analyzing the obtained data, we identified the threshold values of risk factors for uncontrolled BA (vitamin D level $\leq 24.5 \mathrm{ng} / \mathrm{mL}, \mathrm{IL}-17$ level $>83.5 \mathrm{pg} / \mathrm{mL}, \mathrm{BMI}>26.7 \mathrm{~kg} / \mathrm{m}^{2}$ ). Based on our results, it is possible to identify the patients who are at risk of uncontrolled course of the disease.

The values of vitamin D and IL-17 levels could be attributed to drug-modified risk factors. Drug correction of vitamin $D$ is a fairly easy task [22], which cannot be stated about the level of IL-17 [20, 21]. Changing eating behaviors is also a challenge for the patients. A number of authors suggested that patient education and explaining them the risks, associated with their overweight status, could increase their adherence to a balanced diet [23].

An important finding is that an increase in patients' adherence to a healthy diet may contribute to improved treatment outcomes without changing the underlying therapy [24].

Table 7. The relationships of cytokine levels among the study groups

\begin{tabular}{|c|c|c|c|c|c|c|}
\hline \multirow{2}{*}{ Parameters } & Group I $n=27$ & Group II $n=28$ & Group III $n=24$ & \multirow{2}{*}{$U$} & \multirow{2}{*}{$Z$} & \multirow{2}{*}{$p$} \\
\hline & $\mathrm{Me}(\mathrm{IQR})$ & $\mathrm{Me}(\mathrm{IQR})$ & Me (IQR) & & & \\
\hline IL-17 pg/mL & $80.4(64.2-98.6)$ & 93.5 (77.1-104) & 110 (93.6-114.9) & 121 & 3.82 & $<0.05$ \\
\hline IL-10 pg/mL & $17.4(10.4-26.6)$ & $13.58(10.77-18.01)$ & $13.08(8.9-16.5)$ & 236 & 1.65 & $>0.05$ \\
\hline
\end{tabular}

Me, median; IQR, interquartile range. 
Table 8. Dependence of vitamin D levels on BMI

\begin{tabular}{lc}
\hline Group & Statistical significance \\
\hline Normal BMI / Overweight status & $\mathrm{Z}=4.24 \mathrm{p}=0.07$ \\
Normal BMI / Obesity & $\mathrm{Z}=2.24 \mathrm{p}<0.001$ \\
Overweight status / Obesity & $\mathrm{Z}=2.09 \mathrm{p}=0.12$ \\
\hline
\end{tabular}

$\mathrm{BMI}$, body mass index.

\section{Conclusion}

An increase in the energy value of the diet, excessive consumption of the total fat - including at the expense of SFA, cholesterol, and carbohydrates increases the risk of developing an uncontrolled course of BA. The risk of developing an uncontrolled course of BA in patients with a BMI over $26.7 \mathrm{~kg} / \mathrm{m}^{2}$ increases by 5.7 times $(p<0.001)$.

Due to the significant impact of BMI and excessive consumption of the total fat, cholesterol and carbohydrates on disease the course, the analysis of the actual nutrient intake in patients is an important link in a personalized approach to the patient management.

A decrease in the content of vitamin $D$ in the blood serum of less than $24.5 \mathrm{ng} / \mathrm{mL}$ increases the risk of developing an uncontrolled course of BA by 8 times $(p<0.001)$. Hence, low level of vitamin $D$ could be considered a predictor of the uncontrolled BA development.

The formation of $T_{h} 17$ immune response is more typical for overweight patients. The risk of developing an uncontrolled course of BA in patients with IL-17 levels greater than $83.5 \mathrm{pg} / \mathrm{mL}$ increases by 5.2 times $(p=0.003)$.

\section{Ethical approval}

All studies were conducted in compliance with the ethical standards of the Declaration of Helsinki and the European Union directives. All research activities were approved by the Ethics Committee of Samara State Medical University.

\section{Conflict of interest}

We declare that we have no conflicts of interest.

\section{References}

1. Global Initiative for Asthma. Global Strategy for Asthma Management and $\quad$ Prevention. 2021. https://ginasthma.org/wpcontent/uploads/2021/05/GINA-Main-Report-2021-V2-WMS.pdf.

2. Camarinha $C$, Fernandes $M$, Alarcão V, Franco J, Manaças ME, Bárbara $C$, et al. Determinants associated with uncontrolled asthma in Portugal: A national population-based study. Pulmonology 2020: S2531-0437(20)30098-2.

https://doi.org/10.1016/j.pulmoe.2020.02.014.

3. Chen H, Gould MK, Blanc PD, Miller DP, Kamath TV, Lee JH, et al; TENOR Study Group. Asthma control, severity, and quality of life: Quantifying the effect of uncontrolled disease. J Allergy Clin Immunol 2007; 120(2): 396-402. https://doi.org/10.1016/j.jaci.2007.04.040.

4. Russian State Register of Medicinal Preparations. https://grls.rosminzdrav.ru.

5. Zyryanov SK, Dyakov IN, Karpov OI. Modeling of the impact of biological drugs in the economic burden of severe asthma. Good Clinical Practice 2019; (3): 4-12. Russian. https://doi.org/10.24411/2588-0519-2019-10078.

6. Accordini S, Corsico AG, Braggion M, Gerbase MW, Gislason D, Gulsvik $A$, et al. The cost of persistent asthma in Europe: An international population-based study in adults. Int Arch Allergy Immunol 2013; 160(1): 93-101. https://doi.org/10.1159/000338998.

7. Schleich FN, Malinovschi A, Chevremont A, Seidel L, Louis R. Risk factors associated with frequent exacerbations in asthma. Respiratory Medicine: $\quad X \quad 2020 ; \quad 100022$. https://doi.org/10.1016/j.yrmex.2020.100022.

8. von Mutius $\mathrm{E}$, Smits $\mathrm{HH}$. Primary prevention of asthma: From risk and protective factors to targeted strategies for prevention. Lancet 2020; 396(10254): 854-866. https://doi.org/10.1016/j.yrmex.2020.100022.

9. Braido F, Brusselle G, Guastalla D, Ingrassia E, Nicolini G, Price D, et al. Determinants and impact of suboptimal asthma control in Europe: The international cross-sectional and longitudinal assessment on asthma control (LIAISON) study. Respir Res 2016; 17(1): 51. https://doi.org/10.1186/s12931-016-0374-z.

10. Çelebi Sözener Z, Aydın Ö, Mungan D, Mısırlıgil Z. Obesity-asthma phenotype: Effect of weight gain on asthma control in adults. Allergy Asthma Proc 2016; 37(4): 311-317. https://doi.org/10.2500/aap.2016.37.3949.

11. Scott HA, Gibson PG, Garg ML, Wood LG. Airway inflammation is augmented by obesity and fatty acids in asthma. Eur Respir $J$ 2011; 38(3): 594-602. https://doi.org/10.1183/09031936.00139810.

12. Nenasheva NM. The phenotype of bronchial asthma and the choice of therapy. Prakticheskaja pul'monologija 2014; (2): 2-11. Russian. https://elibrary.ru/item.asp?id=23102918.

13. Zakharova IN, Borovik TE, Tvorogova TM, Dmitrieva YuA, Vasilyeva SV Zvonkova NG. Vitamin D: A New Look at the Role in the Body: tutorial. Moscow: RMAPO. 2014; 96 p. Russian.

14. Kupaev VI. Do asthmatics need a diet? Astma i allergija 2015; (4): $21-$ 22. Russian. https://www.elibrary.ru/item.asp?id=26157431.

15. Therapeutic Nutrition: Modern Approaches to the Standardization of Diet Therapy. Tutelyan VA, Gapparov MG, Kaganov BS, Sharafetdinov HH, Eds. Moscow: Dynasty Publishing House. 2010; 301 p. Russian. https://search.rsl.ru/ru/record/01004870372.

16. Kurbacheva OM, Zhestkov AV, Nagatkin DA, Kulagina VV, Nagatkina OV. Modern view on the immunopathogenesis of asthma. Russian Journal of Allergy 2016; 2: 10-14 Russian. https://www.elibrary.ru/item.asp?id=25969699.

17. Wenzel SE. Asthma phenotypes: The evolution from clinical to molecular approaches. Nat Med 2012; 18(5): 716-725. https://doi.org/10.1038/nm.2678.

18. Tomita $Y$, Fukutomi $Y$, Irie $M$, Azekawa $K$, Hayashi $H$, Kamide $Y$, et al. Obesity, but not metabolic syndrome, as a risk factor for late-onset asthma in Japanese women. Allergol Int 2019; 68(2): 240-246. https://doi.org/10.1016/j.alit.2018.10.003.

19. Baiardini I, Sicuro F, Balbi F, Canonica GW, Braido F. Psychological aspects in asthma: Do psychological factors affect asthma management? Asthma Res Pract 2015; 1: 7. https://doi.org/10.1186/s40733-015-0007-1.

20. Beringer A, Noack M, Miossec P. IL-17 in chronic inflammation: From discovery to targeting. Trends Mol Med 2016; 22(3): 230-241. https://doi.org/10.1016/j.molmed.2016.01.001.

21. De Volder J, Vereecke L, Joos G, Maes T. Targeting neutrophils in asthma: A therapeutic opportunity? Biochem Pharmacol 2020. 182: 114292. https://doi.org/10.1016/j.bcp.2020.114292.

22. Papamichael MM, Itsiopoulos C, Lambert K, Katsardis C, Tsoukalas D, Erbas B. Sufficient vitamin D status positively modified ventilatory function in asthmatic children following a Mediterranean diet enriched with fatty fish intervention study. Nutr Res 2020; 82: 99-109. https://doi.org/10.1016/j.nutres.2020.08.004.

23. Shams MR, Fineman SM. Asthma adherence: how can we help our patients do it better? Ann Allergy Asthma Immunol 2014; 112(1): 9-12. https://doi.org/10.1016/j.anai.2013.10.013.

24. Toennesen LL, Meteran H, Hostrup M, Wium Geiker NR, Jensen CB, Porsbjerg $C$, et al. Effects of exercise and diet in nonobese asthma 
patients - A randomized controlled trial. J Allergy Clin Immunol Pract 2018; 6(3): 803-811. https://doi.org/10.1016/j.jaip.2017.09.028.

\section{Authors:}

Vitaly I. Kupaev - MD, PhD, Chair of the Department of Family Medicine, Samara State Medical University, Samara, Russia. https://orcid.org/00000003-2639-0003.

Olga V. Sazonova - MD, PhD, Chair of the Department of Food Hygiene with the course in Hygiene of Children and Youth, Samara State Medical University, Samara, Russia. https://orcid.org/0000-0002-4130-492X.

Maria S. Nurdina - PhD, Instructor, Department of Family Medicine, Samara State Medical University, Samara, Russia. https://orcid.org/00000003-1686-528X

Lyubov M. Borodina - PhD, Associate Professor of the Department of Food Hygiene with the course in Hygiene of Children and Youth, Samara State Medical University, Samara, Russia. https://orcid.org/0000-0002-5765$\underline{8254}$.

Mikhail Yu. Gavryushin - PhD, Associate Professor, Department of Food Hygiene with the course in Hygiene of Children and Youth, Samara State Medical University, Samara, Russia. https://orcid.org/0000-0002-28977700.

Dmitry O. Gorbachev - PhD, Associate Professor, Department of Food Hygiene with the course in Hygiene of Children and Youth, Samara State Medical University, Samara, Russia. https://orcid.org/0000-0002-8044$\underline{9806}$ 